\title{
SOUND AND VIBRATION DAMPING PROPERTIES OF NONWOVEN FLAX REINFORCED ACRYLIC BASED POLYESTER COMPOSITES
}

\author{
WMA Wan Mamat Ali ${ }^{1 *}$, L.E.Ooi ${ }^{1}$, and Z. A Mohd. Ishak ${ }^{2}$ \\ ${ }^{1}$ TheVibrationLab, \\ School of Mechanical Engineering, \\ Universiti Sains Malaysia, \\ ${ }^{2}$ Science and Engineering Research Centre, \\ Engineering Campus, \\ Universiti Sains Malaysia. \\ *Email: amri@usm.my \\ Phone: +6045996346
}

\begin{abstract}
This paper presents the sound and vibration damping properties of nonwoven flax reinforced acrylic based polyester composites. This research attempt to solve the problem of synthetic fibre which caused environmental problems. The goal of is study to characterize the sound absorption and damping properties of the natural fibre at difference thickness and pressure. The nonwoven flax reinforced acrylic based polyester composites are produced by using moulding machines at different compression pressures that are 10,20 and 30 bars. The thicknesses of samples used in this study are 2 $\mathrm{mm}$ and $3 \mathrm{~mm}$. The measurement of sound absorption of the material is carried out using impedance tube. For the sample with $2 \mathrm{~mm}$ thickness, the result shows that the maximum sound absorption of 0.93 was observed at frequency of $853 \mathrm{~Hz}$ and pressure of 20 bars. Damping values are calculated and measure for each sample. The result shows that damping factor is obtained is 0.039 and 0.052 for thickness materials of $2 \mathrm{~mm}$ and $3 \mathrm{~mm}$.
\end{abstract}

Keywords: nonwoven flax reinforced acrylic based polyester composites, vibration damping and sound absorption coefficient.

\section{Introduction}

Today, noise pollution has become a new pollution source that caused bad influence to the environment, human health and national economy. Researchers have carried out various noise control methods for investingating the issue. The mechanism of controlling noise included active control and passive control [1]. Recent years, researchers have focus on natural fibers such as kenaf, ramie and jute reinforced composites. The reason is good mechanical properties, light weight, environmentally friendly and biodegradable $[2,3]$.

Multiple layered coir fiber absorbers involving air spaces and micro-perforated plate has been studied both through simulation and experiments [4-5]. The absorption performance of industrial waste tea leaf fibre has been studied by Ersoy and Kucu [6]. 
They found that the absorption coefficient of the fibres increases significantly when backed with a single woven cotton cloth. Three types of natural fibres which are ramie, flax and jute in a form of composites has been studied by Yang and Li [1]. It is found that the natural composites had satisfying noise reduction ability similar to that of the synthetic fibres. Noise control panels made from vegetable fibers consisting coconut, palm, sisal and açaí is proposed by Bastos et al. [7]. It was found that the performance of vegetable fibers could be greater in certain cases when compared to the synthetic acoustic foam materials. Subsequently, sound absorption properties of kapok fibers have been studied by Xiang et al. [8]. The authors found out that kapok fibres have similar acoustics performance with the combinations of commercial glass wool and cotton fibres although the bulk density of kapok fibre is lower. Putra et al. [9] studied sugarcane waste fibers and found that the sound absorption coefficient is comparable with those of commercial synthetic fibers. The review shows that there have been many studies performed on natural material based which take advantage of both natural materials as well as superior mechanical performance over metallic structures and also it has good sound absorbing and vibration damping properties [10]. These natural materials could essentially be grown for the purpose of manufacturing composites, in turn providing such benefits as being both biodegradable and recyclable.

The goal of this study is to explore the sound absorbing and damping properties of composites composed with natural materials and compare them over commonly used traditional composites, such as glass-reinforced composites.

\section{Experimental Measurement}

\section{Material preparation}

Natural fiber is capable of replacing glass fiber and synthetic fibers in automotive and construction industries, due to its lightweight and low costs [11], [12]. In addition, natural fiber such as kenaf, hem, flax, jute and sisal reinforced composites can reduce the weight and manufacturing cost, reducing the use of carbon dioxide (CO2) for manufacturing, recyclable and the main benefits are "green" and environmentally friendly. In this research, a non-woven flax material is used to produce non-woven flax reinforced acrylic based polyester composites. The material used is Acrylic Based Polyester resin (Acrodur) 950L with a real density of $1300 \mathrm{~g} / \mathrm{m}^{2}$.

Flax fiber material (non-woven flax) is cut according to the desired size, and the fiber section will be placed in air circular oven for 12 hours at $60 \pm 5^{\circ} \mathrm{C}$ in order to ensure the material is fully dry and free from moisture. Next, the material is immersed into the liquid of Acrodur $950 \mathrm{~L}$ resin for 5 minutes and then dried for 30 minutes in the circular oven. The materials are been inserted into the hydraulic hot press machine at temperature of $210^{\circ} \mathrm{C}$. The materials are pressed using the hydraulic hot press machine at difference pressures that are at 10 bars, 20 bars and 30 bars. For this process, the time is set for six minutes for each press. Figure 1 shows the compression mold machine that used in this research. Finally, the materials are cut using the shear machine according to the shape and size required. 


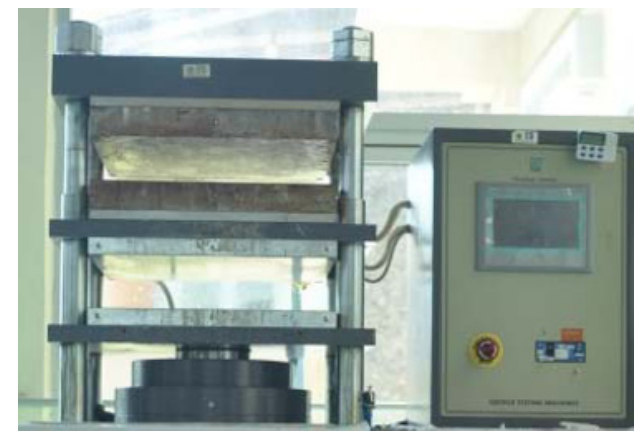

Figure 1: Compression Mould Machine

\section{Sound absorption coefficient measurement}

Sound absorption coefficient of each sample is measured using impedance tube, LMS Scadas Mobile, LMS software (LMS Sound Absorption Coefficient) and two units of microphones (BSWA MA211) as shown in Figure 2. The plunger is used to control the air gap. Microphones are calibrated each time before measurement. The samples used in this measurement are prepared in $2 \mathrm{~mm}$ and $3 \mathrm{~mm}$ as shown in figure 3 . The loudspeaker was used as a sound source for the impedance tube that connected to one end as illustrated in Figure 2. The loudspeaker generates the broadband random sound waves and the sound waves propagating as plane waves in the tube hit the sample, get partially absorbed, and subsequently reflected. The acoustical properties of the test sample were tested in the frequency range of 100-1500 Hz. This system tests a sound absorptive material, processes the results, and reports the results in a graph of the absorption coefficient in various frequencies. Thus, the absorption coefficient of each sample was obtained. Table 1 list out the dimensions and pressure for different specimens used in this research.

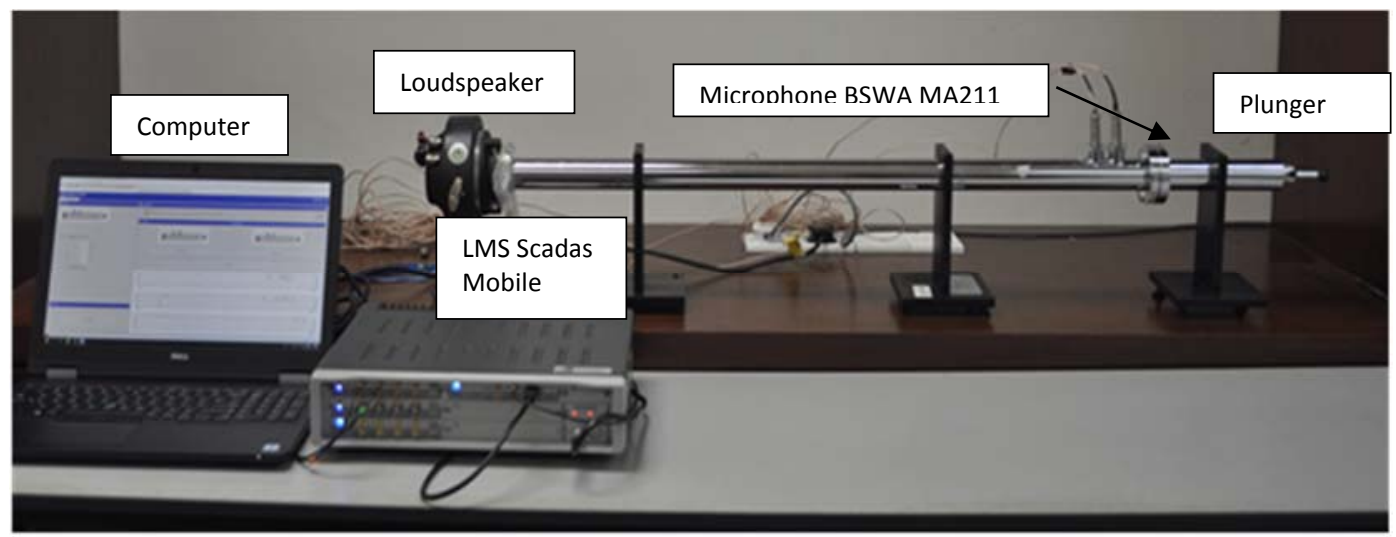

Figure 2: The setup experiment of the sound absorption coefficient. 
Table 1: Dimension of sound test specimens

\begin{tabular}{|c|c|c|c|}
\hline Pressure (bar) & Thickness $(\mathrm{mm})$ & Diameter $(\mathrm{mm})$ & Weight (grams) \\
\hline 10 & 2 & 34.8 & 1.87 \\
\hline 20 & 2 & 34.8 & 1.82 \\
\hline 30 & 2 & 34.8 & 1.77 \\
\hline 10 & 3 & 34.8 & 1.82 \\
\hline 20 & 3 & 34.8 & 1.84 \\
\hline 30 & 3 & 34.8 & 2.02 \\
\hline
\end{tabular}

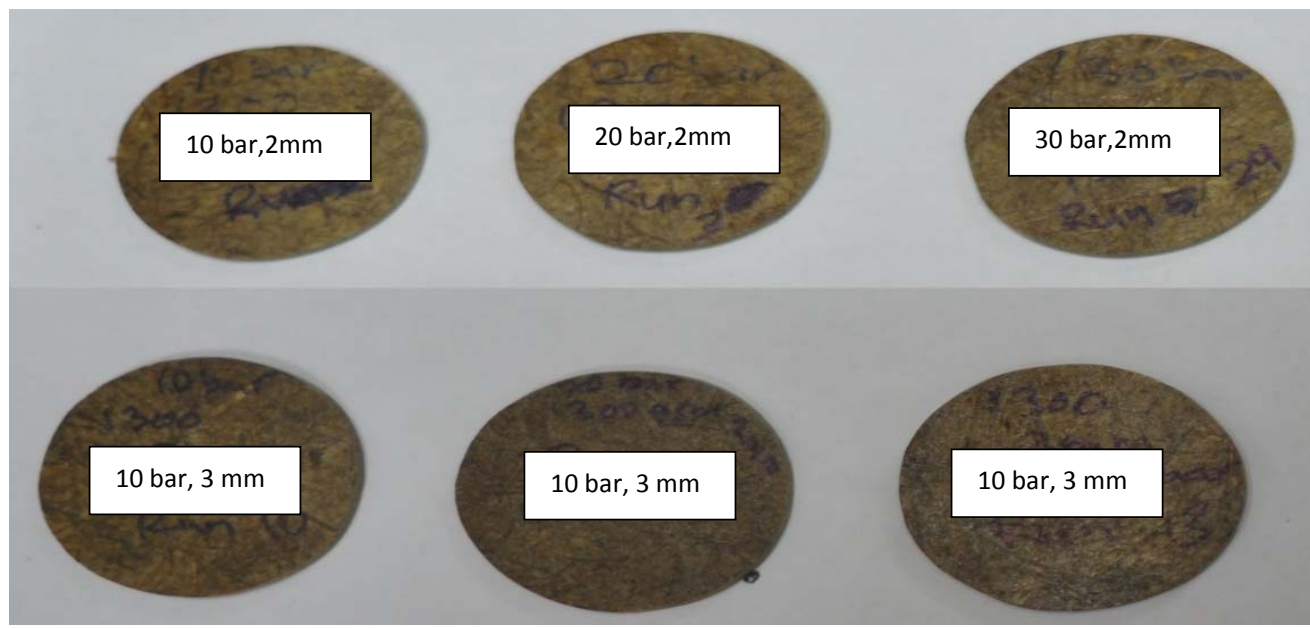

Figure 3: Sound Test Specimens of thickness of $2 \mathrm{~mm}$ and $3 \mathrm{~mm}$

\section{Vibration damping factor measurement}

Free vibration method is used to measure damping properties of each sample as shown in Figure 5. The specimens are cut according to the desired size of the different specimens as shown in Table 2 and Table 3. The specimen is mounted on cantilever beam structure and tied with a fixture. A Dytran accelerometer (model Model 3224A2) sensor with sensitivity of $2.89 \mathrm{mV} / \mathrm{g}$ is placed at the end of the specimen. Output signals are received by connecting the accelerometer sensor with Data Acquisition of LMS Scadas Mobile which is connected to Personal Computer (PC) with LMS Test Xpress software.

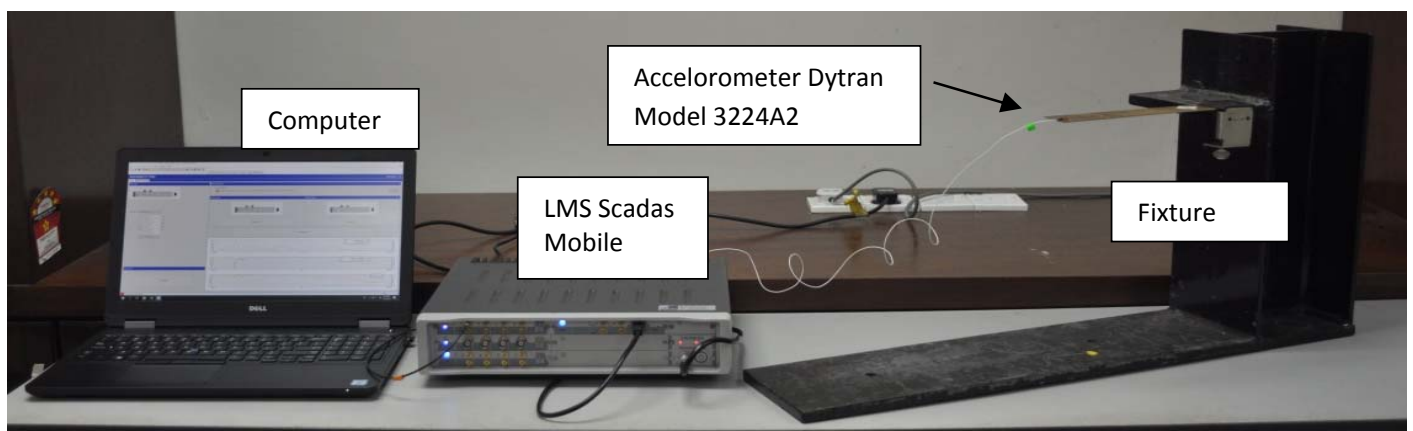

Figure 5: Vibration damping test set up 
Table 2: Dimensions of vibration test specimens ( $2 \mathrm{~mm}$ and $3 \mathrm{~mm})$

\begin{tabular}{|c|c|c|c|}
\hline Pressure (bar) & Thickness $(\mathrm{mm})$ & Length $(\mathrm{mm})$ & Width (grams) \\
\hline 10 & 2 & 210 & 35 \\
\hline 20 & 2 & 210 & 35 \\
\hline 30 & 2 & 210 & 35 \\
\hline 10 & 3 & 210 & 35 \\
\hline 20 & 3 & 210 & 35 \\
\hline 30 & 3 & 210 & 35 \\
\hline
\end{tabular}

Figure 6 shows the vibration response of the specimen over time. The damping factor is calculated by taking the highest value and the lowest value at the peak of the graph in the waveforms obtained. Then take some number of peak graphs for the damping factor calculation $(\zeta)$ and the values obtained are included in equations 1 and 2.

$$
\begin{gathered}
\delta=\frac{1}{\eta} \ln \left(\frac{y_{0}}{y_{n}}\right) \\
\zeta=\frac{1}{\sqrt{1+\left(\frac{2 \pi}{\delta}\right)^{2}}}
\end{gathered}
$$

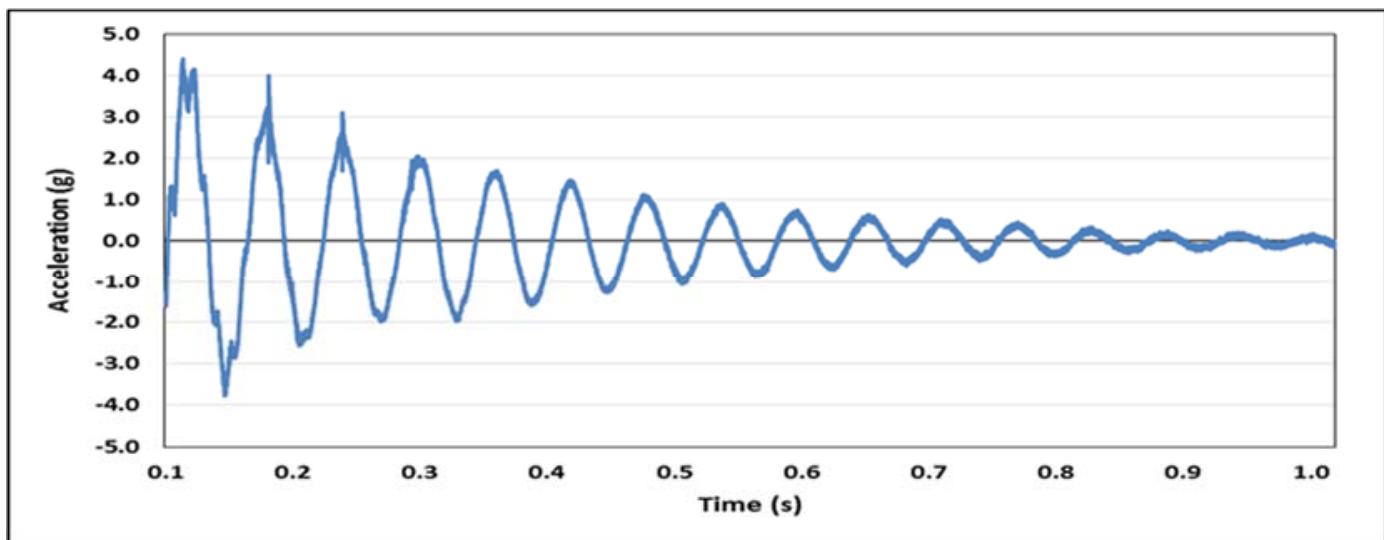

Figure 6: Free vibration response of the composite

Results and discussions.

\section{Analysis of sound absorption coefficient measurement}




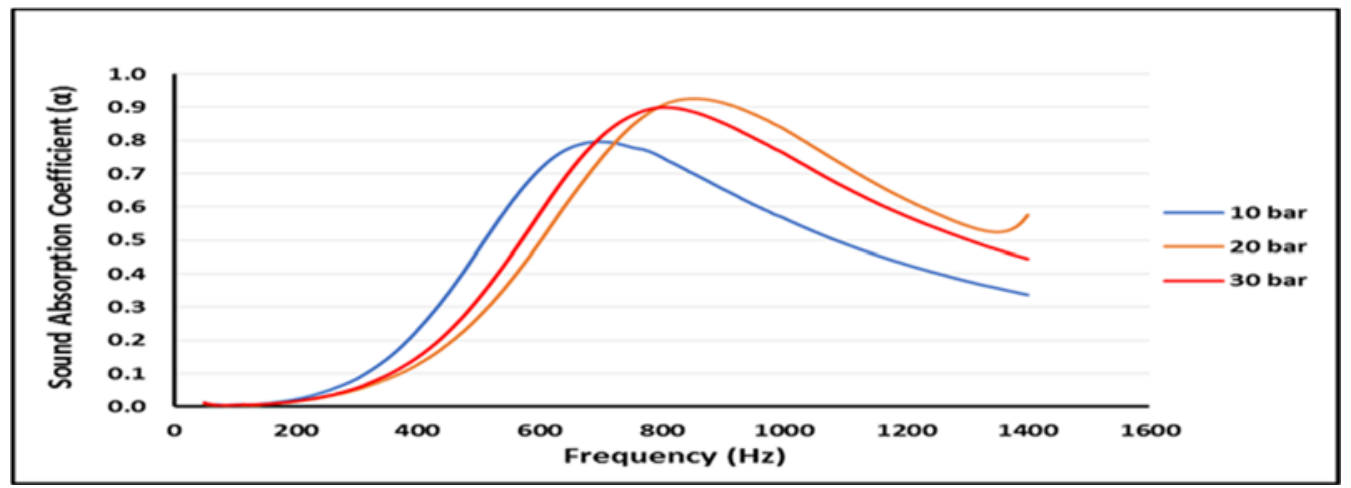

Figure 7: Sound absorption coefficient for specimen with thickness of $2 \mathrm{~mm}$.

Figure 7 shows the results of sound absorption coefficient for specimen of thicknesses of $2 \mathrm{~mm}$. In figure 7, the sound absorption coefficient increases with the frequency and reaches the maximum value and then begins to decrease as the frequency is increased. The maximum sound absorption coefficient for specimen at preesure 20 bar reach 0.93 at frequency of $853 \mathrm{~Hz}$. For sample with pressure of 10 bars, sound absorption coefficient os 0.80 at frequency of $700 \mathrm{~Hz}$. While for sample at $30 \mathrm{bars}$, it is observed that the sound absorption coefficient of 0.90 is recorded at frequency of 803 Hz.

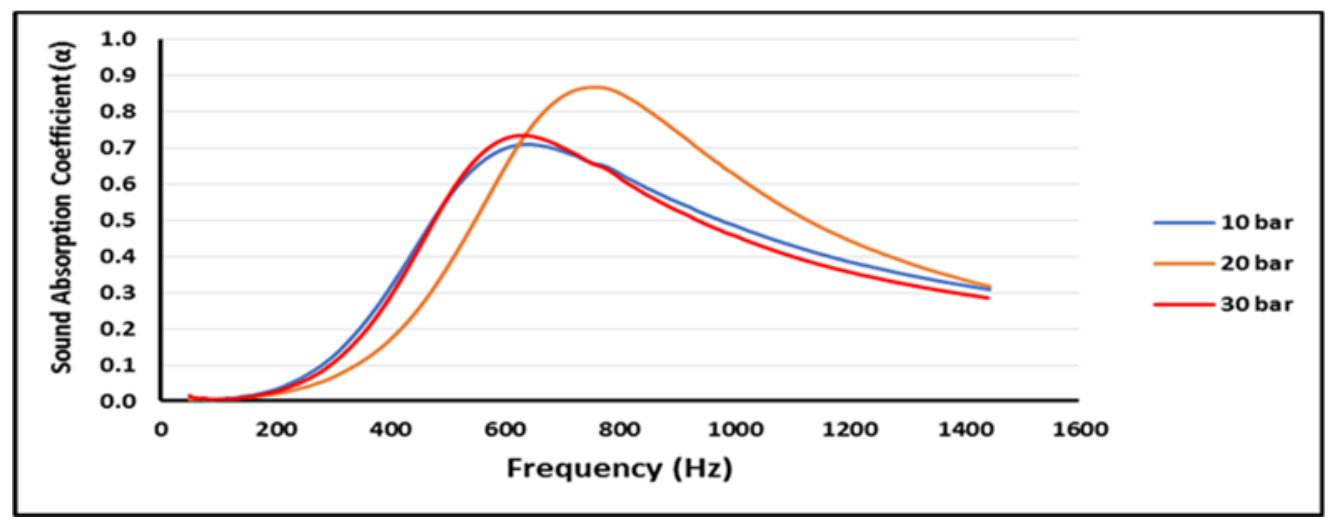

Figure 8: Sound absorption coefficient for specimen with thickeness of $3 \mathrm{~mm}$.

Figure 8 shows the results of sound absorption coefficient for specimens with thicknesses of $3 \mathrm{~mm}$. The figure shows sound absorption coefficient increases with the frequency and reaches the maximum values and begins to decrease as the frequency is increased. The maximum sound absorption coefficient of 0.87 is achieved at frequency of $760 \mathrm{~Hz}$ for sample with pressure of 20 bars. For sample with pressure of $10 \mathrm{bars}$, 0.71 of sound absorption coefficient was observed at frequency of $640 \mathrm{~Hz}$. While for samples at 30 bars, it is observed that the sound absorption coefficient of 0.73 is observed at frequency of $803 \mathrm{~Hz}$. 


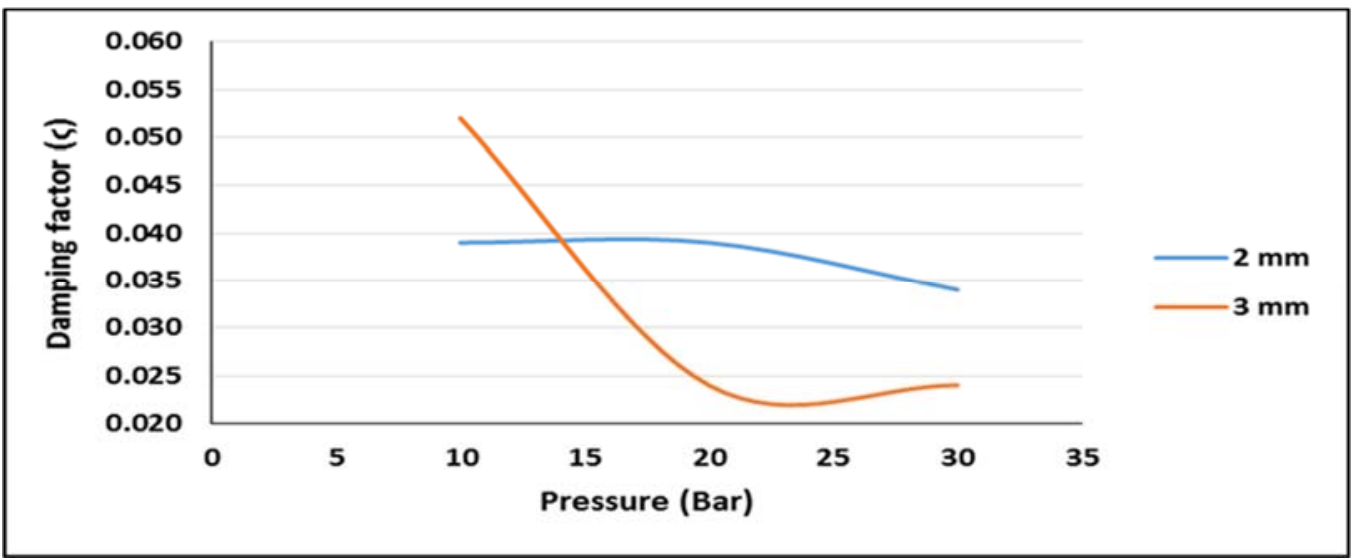

Figure 9: Damping ratio for specimen $2 \mathrm{~mm}$ and $3 \mathrm{~mm}$ under different compression pressure (bar)

Figure 9 shows the result of damping ratio for specimen of thickness of $2 \mathrm{~mm}$ and 3 $\mathrm{mm}$ for nonwoven flax reinforced acrylic based polyester composites that measured by LMS Test Xpress software. For specimen with thickness of $2 \mathrm{~mm}$, the maximum damping factor is 0.039 at pressure of 10 bars and 20 bars. The damping factor slightly drops to 0.034 when the pressure is increased to 30 bars. For specimen with thickness of $3 \mathrm{~mm}$, the maximum damping factor is 0.052 at pressure of 10 bars. The damping factor drop to its minimum point at 20 bars and increased to 0.024 at pressure of 30 bars. The measured SAC and damping factor in this paper obtained is archived similar trend compared to research conducted by Prabhakaran et al. [10] which produced the SAC and damping ratio of 0.45 and 0.014 respectively.

\section{Conclusion}

Nonwoven flax reinforced composite fibres have been shown to possess good sound absorption through the impedance tube measurement. The normal-incidence sound absorption coefficient of nonwoven flax fibre is found to have value of 0.93 at $853 \mathrm{~Hz}$ for specimen with thickness of $2 \mathrm{~mm}$ and pressure of 20 bars. Increasing the pressure can further enhance the sound absorption coefficient. These results suggest that the nonwoven flax reinforced composites could be viable candidate for applications which need of good sound and vibration properties.

\section{Acknowledgement}

The authors would like to gratefully acknowledge Universiti Sains Malaysia (USM) Short Term Research Grant [grant no. 60313028] for funding the project.

\section{References}

[1] W. Yang and Y. Li, "Sound absorption performance of natural fibers and their composites," Sci. China Technol. Sci., vol. 55, no. 8, pp. 2278-2283, 2012.

[2] A. K. Mohanty, M. Misra, and L. T. Drzal, "Surface modifications of natural fibers and performance of the resulting biocomposites: an overview," Compos. interfaces, vol. 8, no. 5, pp. 313-343, 2001.

[3] H. Cheung, M. Ho, K. Lau, F. Cardona, and D. Hui, "Natural fibre-reinforced 
composites for bioengineering and environmental engineering applications," Compos. Part B Eng., vol. 40, no. 7, pp. 655-663, 2009.

[4] M. J. M. Nor, N. Jamaludin, and F. M. Tamiri, "Effect of perforated panel in acoustics absorption performance of coir fiber material," in 12th International Congress on Sound and Vibration 2005, ICSV 2005, 2005.

[5] M. J. M. Nor, N. Jamaludin, and F. M. Tamiri, "A preliminary study of sound absorption using multi-layer coconut coir fibers," Electron. J. Tech. Acoust., vol. 3, pp. 1-8, 2004.

[6] S. Ersoy and H. Küçük, "Investigation of industrial tea-leaf-fibre waste material for its sound absorption properties," Appl. Acoust., vol. 70, no. 1, pp. 215-220, 2009.

[7] L. P. Bastos, G. da S. V. de Melo, and N. S. Soeiro, "Panels manufactured from vegetable fibers: An alternative approach for controlling noises in indoor environments," Adv. Acoust. Vib., vol. 2012, 2012.

[8] H. Xiang, D. Wang, H. Liua, N. Zhao, and J. Xu, "Investigation on sound absorption properties of kapok fibers," Chinese J. Polym. Sci., vol. 31, no. 3, pp. 521-529, 2013.

[9] A. Putra, Y. Abdullah, H. Efendy, W. M. Farid, M. R. Ayob, and M. S. Py, "Utilizing sugarcane wasted fibers as a sustainable acoustic absorber," Procedia Eng., vol. 53, pp. 632-638, 2013.

[10] S. Prabhakaran, V. Krishnaraj, and R. Zitoune, "Sound and vibration damping properties of flax fiber reinforced composites," Procedia Eng., vol. 97, pp. 573$581,2014$.

[11] S. Taj, M. A. Munawar, and S. Khan, "Natural fiber-reinforced polymer composites," Proceedings-Pakistan Acad. Sci., vol. 44, no. 2, p. 129, 2007.

[12] M. J. John and S. Thomas, "Biofibres and biocomposites," Carbohydr. Polym., vol. 71, no. 3, pp. 343-364, 2008.

[13] Z. Hong, L. Bo, H. Guangsu, and H. Jia, "A novel composite sound absorber with recycled rubber particles," J. Sound Vib., vol. 304, no. 1-2, pp. 400-406, 2007.

[14] E. Gliscinska, M. Michalak, I. Krucinska, J. Kazimierczak, A. Bloda, and D. Ciechanska, "Sound absorbing composites from nonwoven and cellulose submicrofibres," J. Chem. Chem. Eng., vol. 7, no. 10, p. 942, 2013. 